This item was submitted to Loughborough's Research Repository by the author.

Items in Figshare are protected by copyright, with all rights reserved, unless otherwise indicated.

\title{
Introducing the student designer to the role of emotion in design
}

PLEASE CITE THE PUBLISHED VERSION

PUBLISHER

(c) Taylor and Francis

LICENCE

CC BY-NC-ND 4.0

REPOSITORY RECORD

Denton, Howard G., D.C. McDonagh, S. Baker, and Paul Wormald. 2019. "Introducing the Student Designer to the Role of Emotion in Design". figshare. https://hdl.handle.net/2134/2251. 
This item was submitted to Loughborough's Institutional Repository by the author and is made available under the following Creative Commons Licence conditions.

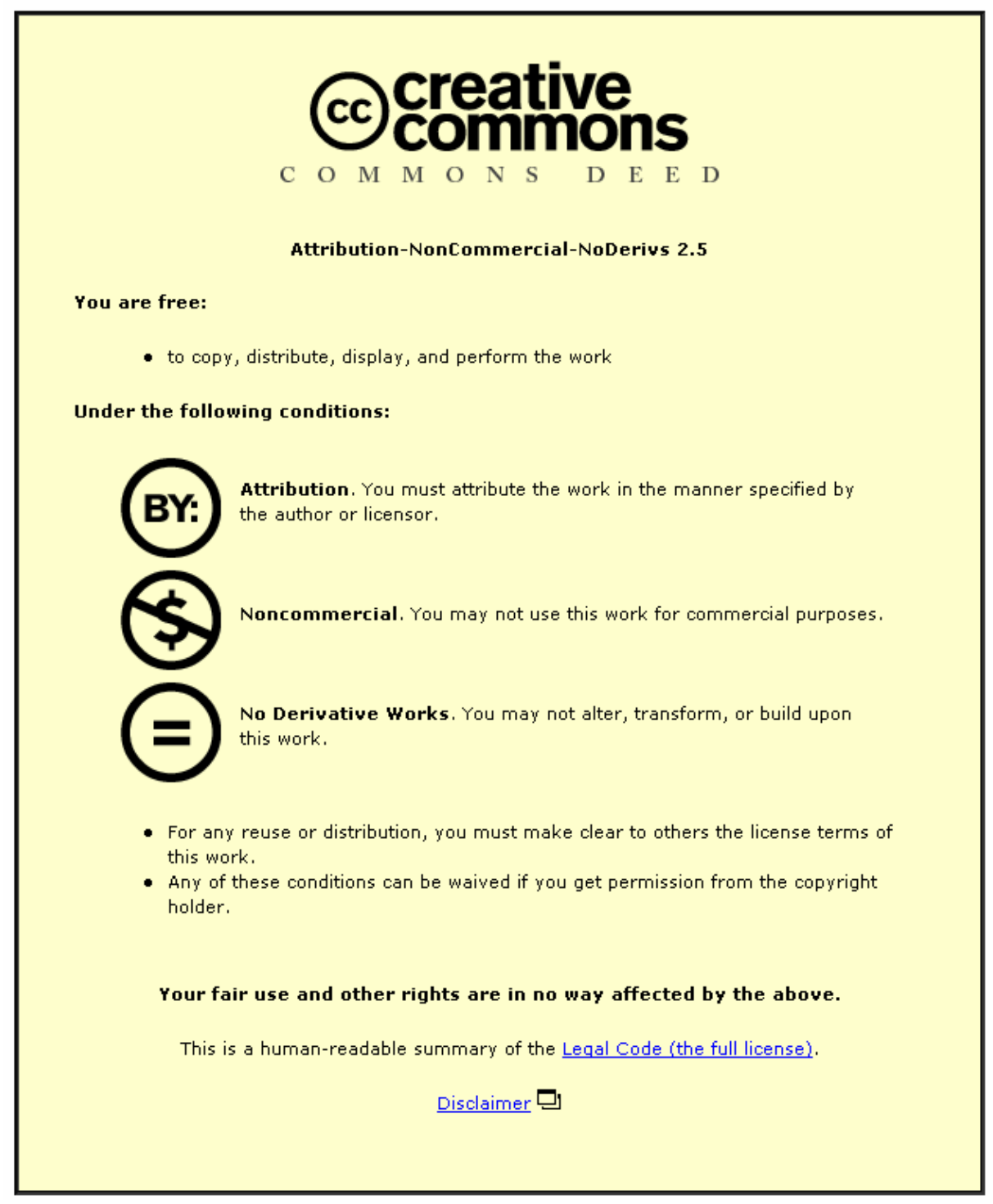

For the full text of this licence, please go to: http://creativecommons.org/licenses/by-nc-nd/2.5/ 


\title{
Loughborough
University
}

\section{Introducing the student designer to the role of emotion in design}

\author{
Denton H G, McDonagh D, Baker S and Wormald P
}

\section{INTRODUCTION}

No matter how elegant and functional a design is it will not win a place in our lives unless it can appeal at a deeper level, to our emotions. (Sweet: 1999)

Products satisfy needs beyond the functional. These needs may include aspirations, emotions, cultural and social needs. It is crucial that designers are equipped to deal with the emotional domain of products and users. Carlson (1997) considered emotion to be short term waves of feeling arising without conscious effort, whereas mood, is defined as a longer termed state with less intensity. The authors' working definition of the 'emotional domain' is the range of states of mind (which may influence the body) and which are influenced by internal and external stimuli. These effects tend to be transient although an individual will have a tendency towards a particular state, such as melancholy, happiness, calmness and so on. But even here various stimuli can cause a significant swing in state of mind. But this is a highly individual effect for example, one person may find the new iMac computer delightful and cheerful, where as others, may find it irritating and repulsive.

The authors recognise that this concept of the emotional domain may be a mind shift for many students. Anybody who has engaged in and completed a significant design project, such as that usually undertaken at A level in the UK will have had a strong emotional involvement with the project, whether it be aesthetically or technologically based design work. However, the authors experience of working with new undergraduates indicated that post-A level students did not seem to recognise the full implications and potential for emotion in design work. Teachers of Design and Technology in UK schools appear not to explore this domain to any extent, possibly due to the intangible nature of the concept. Teaching students to recognise the value of an emotional input to design work and to employ such approaches successfully is not straightforward. Therefore, in planning, teaching and learning staff need to approach the exploration of such concepts over an extended period of time and using a range of appropriate techniques, some of which are discussed in this paper. It should certainly be introduced early in an industrial design degree programme and be centred on activities which generate discussion and enable them to explore the concepts within the designing of products. The aim of this paper is to describe and 
analyse the way in which students are introduced to the emotional domain in relation to product design at Loughborough through the first semesters design practice experience. The module is described and staff thinking and objectives are outlined. The student background is described. The method employed in analysis is described. Results given and discussed.

\section{BACKGROUND}

The Department of Design and Technology at Loughborough University, takes approximately 130 undergraduates on to its programmes of industrial design and technology each year. The practice of design is developed through two first year modules, the first of which is the subject of this paper and has been the subject of several papers (Baker et al 2000: McDonagh-Philp and Lebbon 2000).

The first exercise, the 'Outwoods' project has multiple aims including introducing students to each other and to the staff team. The project employs a fantasy context: that the students are small, nomadic groups of five, travelling open countryside and using portable shelters. These are designed and constructed in a nearby wooded area. Students are encouraged to use their imagination and emotional responses in relation to this context, to relax, be comfortable and unconstrained. The shelters are not simply functional, they must also reflect the chosen 'character' (e.g. priests, herbalists, warriors) and stated emotions of each group in their form. This means they also have a sculptural, expressive form.

Teamwork is used to encourage an openness of ideas and communication. This results in students sharing and developing their responses to the characterization and emotional aspects of the design task.

Students are encouraged to explore the aesthetic possibilities in both the overall form and the detail of the structures. For example, bindings should be aesthetically pleasing; materials should be used and combined in harmonious and pleasing manners; these are emotional aspects of design.

Immediate post-exercise evaluation (Denton 2002) revealed whilst most students find the fantasy context difficult to grasp it is, interestingly, males who are more accepting. Subsequent projects expand on this approach in different contexts to help develop the sensitivity to design and emotion.

The second exercise, the hand project, firstly requires the students to design and make an articulated model of a human hand, using only white card. Secondly, they use found materials to make a hand which should express an aspect of personality or character. The first section is an exercise demanding precision, observation and modelling skills. Students are encouraged to work in pairs (again encouraging discussion to assist in externalising/expressing their emotional responses to the design tasks) and explore the manipulation of card in an expressive way as well as to open up their preconceived ideas of simulating movement. This often results in sculptural and innovative responses.

The third exercise requires the production of a 3D-card model to hold a pen, which will sit on a desk. They have to design the artefact so that it reflects the 'essence' of themselves (e.g. personality, influences, style, preferences and energy). This two-day project further refines ideas presented in the previous projects. It has two aspects. The first is to produce a 'crisp' desktop penholder. This requires cleanliness and precision. Students explore the emotional adjectives that are used 
to convey 'being held' and to communicate this expressively by the use of form, texture, scale, colour and their innovative manipulation of card.

A further exercise focuses on the use of colour to effect the subliminal message of a product. Students work in groups (discussion again) to produce a mood board, working in a given colour. This is supported by lectures on colour symbolism. Individually, the students use this mood board to re-style a product.

\section{METHOD}

In order to access students reactions to emotional aspects of design, it was decided that a discussion based methodology was most appropriate as by then the group had become familiar with each other and open communication. A focus group was conducted with a sample group (8 females and 13 males), all in the 18-19 age range. The focus group was guided by a set of questions whilst allowing fluid discussion to encourage students to raise issues important to them. Notes were made by two independent scribes and immediately transcribed for analysis. A summary of the findings are presented below and discussed in context.

\section{RESULTS/DISCUSSION}

What do the you think is the relationship between design and emotion?

Students recognised that users have emotional responses to products beyond the functional. They reported that design can create an image, a style and 'spark a feeling' in the user. Colour and texture were identified as important elements. They stated that both the designer and user want to use a product to express their own personality; to project an image of self or one they aspire to (the power of branding). The students also recognised that people react individually and that a designer needs to be able to 'cater for a range of emotions in one design'.

These findings indicate that the student group were, by then, ready to discuss to discuss such concepts and appeared to have grasped a basic understanding of the relationship of design and emotion.

What role do you think emotion has in design?

Two main issues emerged. Firstly, emotion was perceived as the 'fuel for design'. This student statement was supported within the group and illustrates a positive role for emotion in terms of driving concept ideation. Secondly, students perceived emotion as linking the 'character' of a product with marketing as an important selling point. This point was followed up by some students who noted that a designer/marketer 'play on emotions to seduce the buyer'; a negative and rather cynical view for an undergraduate designer, but reflects a positive moral stance nonetheless. They emphasised emotion in design enhancing the quality of life for the user, which was revealing.

The group had, therefore, recognised roles for emotion in design from a number of perspectives, and yet, had a healthy moral regard for the dangers of 'seducing' the buyer by manipulating their emotions.

Has your view changed because of the module? 
They felt that introducing and integrating the emotional domain enhanced their design solutions while helping them to overcome 'superficiality', meaning they now perceive industrial/product design to be more than just as a mere styling activity. Some reported that they had previously at a school level tended to design a product from the 'inside out' - 'I got it working and then covered it'. Now they appreciated the value of a more holistic approach. Students considered that the rapid sketching and exploration pushed by module staff, whilst at first difficult, is now helping them explore ideas further and actually promotes the integration of emotion. Slow, deliberate drawing appears to limit the expression and integration of emotion at the concept generation stage. Many of the students reported that their work at school level was not helping them to communicate design ideas and they tended to be extremely reliant on the use of words and text rather than sketching and modelling. They felt their ideas were now more realistic and that they were more in tune with real world constraints. Colour was specifically highlighted as a tool a designer can use in relation to emotion, though their appreciation of this was at a basic stage. There had been a number of elements of exercises which involved the exploration of colour and its emotional impact.

Brainstorm which activities have involved emotion.

The group listed all the activities conducted; students recognised that all had an emotional content but they particularly singled out the mood board exercise, the hand project and the nomadic brief. They felt that individual student input by its nature is emotional. They recognised that staff encouraged this.

What particular aspects of the module work has had the most impact in relation to design and emotion?

The module had led to them considering the personality of the designer being of paramount importance (sympathetic, proactive, imaginative, creative, team member, expressive, worldly, wide knowledge). They expressed the need to 'live and breath design'. Emotion was perceived as essential to 'good design' as well as the designer being emotionally involved within design, they identified the need for the designer to be aware of users emotions. This raises issues on a designers ability to design for others outside their own experiences.

Has anything had an adverse effect on design and emotion in this module?

The main area of concern for the students was the way in which they found themselves immediately immersed within the module. They expressed the desire for more time to develop their drawing skills, gain more confidence and have more time to bond with fellow students. Staff do not necessarily agree that a 'gentler' approach would be appropriate. One intention, was to punch through the usual 'noise' of the first month of so of undergraduate life to establish the key points of design practice, including the value of the emotional domain.

Describe the perfect designer.

The students identified that being sympathetic as a designer is a crucial attribute, alongside being able to work concurrently on a number of tasks, and thinking on a number of levels at any one time. Emotion was perceived as being an important input to design, which differentiated designers from engineers. They felt that it is 
advantageous to be emotional for a designer but that this may not help the engineer.

\section{'Designers become dream catchers' \\ 'Emotion fuels design'}




\section{CONCLUSION}

There were strong indications from the group that the focus on emotional dimensions within design work at the University were new to them and a mind shift. At a school level (pre-degree) students, on the whole, were not explicitly encouraged to respond emotionally to project work or to have discussed this dimension with teachers or amongst themselves. This, of course, would require further investigation before any firm conclusions could be drawn. Certainly the findings indicated that students recognised the emotional domain as an overt objective of the staff within the module described. Whilst not all found it easy to adjust to this approach, the post-module focus group brought a unanimous agreement that the objective was sound and related to 'good' design practice and was appropriate to undergraduate training. The student cohort responded well to the introduction and integration of this paradigm and recognised the importance of the emotions within design.

The one negative area uncovered was that of students questioning the moral value of what some perceived as a 'seduction' by manipulating emotions. This is an interesting point and certainly such moral questions must be a part of any under graduate design training. The question of where seduction in a negative sense starts and a positive process of giving the purchaser or buyer a product which they can use to enhance their lives and project their personality is an important one.

Students in the early stages of a degree programme may feel exposed and vulnerable. This may be exacerbated by requiring them to respond emotionally to projects, especially as they are required to discuss their feeling in 'public'. Nevertheless, staff perceive this ability to communicate and share emotional reactions as being central to the development of sensitivity in design. Therefore, it is essential that this importance is signalled overtly in the early stages of design training, and the process is continued throughout design training.

\section{REFERENCES}

Baker, S. Wormald, P., McDonagh-Philp, D. and Denton, H. 2000, Sthira, sukha: Introducing industrial design undergraduates to softer design issues. International Conference on Design Education, Curtin University of Technology, Perth, Western Australia. 11-13 December, pp.94-102.

Carlson, R. 1997, Experienced Cognition. (NJ, USA: Lawrence Erlbaum).

Denton, H. G. 2002, Starting a design course with a bang: warming up a new group and ensuring key principles are internalized at the start of an undergraduate programme. The Design Journal, 4 (3) pp. 41-49.

McDonagh-Philp, D. and Lebbon, C. 2000, The Emotional Domain in Product Design. The Design Journal 3(1) pp.31-43.

Sweet, F. 1999, Frog: Form Follows Emotion. (London: Thames and Hudson) 